\title{
On the formation of floating metal laminæ
}

\section{F. Mylius \& O. Fromm}

To cite this article: F. Mylius \& O. Fromm (1894) On the formation of floating metal laminæ, Philosophical Magazine Series 5, 38:231, 248-248, DOI: 10.1080/14786449408620628

To link to this article: http://dx.doi.org/10.1080/14786449408620628

曲 Published online: 08 May 2009.

Submit your article to this journal

Џ Article views: 2

Q View related articles $₫$ 
the observations were most carefully made, and some of them were repeated by Messrs. Cagnato and Strapazzon.

The result arrived at by me is considered incorrect by Messrs. Ramsay and $\dot{Y}$ oung - that "the vapour-pressure at a given temperature depends on the relative volumes of liquid and gas," because it is "absolutely opposed" to their experiments, and they thus maintain that my liquids must have contained some other liquid, or that they contained a permanent gas.

But I reply that the memoirs which describe my experiments detail all the minute care taken by me in order to obtain pure liquids; and they also give the calculation (in the case of ether and of carbonic sulphide) which shows that the increase of pressure could not be attributed to gas which might casually have remained in the experimental globe.

I would rather observe that, in order to observe such a phenomenon, an apparatus is necessary which enables us-as in my case--slowly to compress the vapour, and to maintain it for a time under constant pressure.

\section{ON THE FORMATION OW FLOATING METAL LAMINA. BY F. MYLIUS AND O. FROMM.}

The following are the results of this investigation :-

1. Oxidizable metals such as zinc, iron, cobalt, cadmium, copper, silver, and antimony, have the property that when separated by electrolysis they float on the surface of solutions of their salts in coherent lamius.

2. This diffusion depends on two circumstances-firstly, the presence of an impurity which does not mix with water; and, secondly, the chemical action of the oxygen present. The same effect is produced by sulphur on the halogens.

3. For the spreading of the metals on the boundary of two media, the thickness of the oily layer is not of essential importance.

4. The form of the bounding surface has no appreciable influence on the phenomenon: hence the spreading occurs even when one medium is in the form of drops.

5. Oxides and sulphides which conduct the current hare the property of spreading out on the bounding surface; thus, for instance, the lower degrees of oxidation of silver and of cadmium, peroxide of lead, subsulphide of copper.

6 . The growth of the floating lamina is influenced by the capillary attractions which those parts of the liquid experience from which the precipitate is deposited.

7. During the passage of the current a tension is often observed wbich disappears when the current is broken, and apparently depends on the difference of potential, like the surface-tension of mercury when it is polarized.-Wiedemann's Annalen, No. 4, 1894. 